\title{
Raman Optical Activity (ROA) as a New Tool to Elucidate the Helical Structure of Poly(phenylacetylene)s
}

Luis Palomo, Dr. Rafael Rodríguez, Samara Medina, Prof. Emilio Quiñoá, Prof. Juan Casado, Prof. Félix Freire, Prof. Francisco J. Ramírez

\section{Accepted Author Manuscript}

This is the peer reviewed version of the following article: L. Palomo, R. Rodríguez, S. Medina, E. Quiñoá, J. Casado, F. Freire, F. J. Ramírez, Angew. Chem. Int. Ed. 2020, 59, 9080, which has been published in final form at https://doi.org/10.1002/anie.202000651. This article may be used for non-commercial purposes in accordance with Wiley Terms and Conditions for Use of SelfArchived Versions

\section{How to cite:}

L. Palomo, R. Rodríguez, S. Medina, E. Quiñoá, J. Casado, F. Freire, F. J. Ramírez, Angew. Chem. Int. Ed. $2020,59,9080$

\section{Copyright information:}

(C) 2020 Wiley-VCH Verlag GmbH \& Co. KGaA, Weinheim. This article may be used for noncommercial purposes in accordance with Wiley Terms and Conditions for self-archiving 


\title{
Raman Optical Activity (ROA) as a New Tool to Elucidate the Helical Structure of Helical Polymers
}

\author{
Luis Palomo, ${ }^{\mathrm{a} \ddagger}$ Rafael Rodríguez, ${ }^{\mathrm{b}}{ }^{\ddagger}$ Samara Medina, ${ }^{\mathrm{a}}$ Emilio Quiñoá, ${ }^{\mathrm{b}}$ Juan Casado, ${ }^{\mathrm{a}}$ Félix Freire $^{\mathrm{b}^{*}}$ and \\ Francisco J. Ramírez ${ }^{\mathrm{a}^{*}}$
}
[a] L. Palomo, S. Medina, Prof. J. Casado, Prof. J. Ramírez Departamento de Química Física, Facultad de Ciencias Universidad de Málaga
Campus de Teatinos, Málaga 29071, Spain
E-mail: ramirez@uma.es
[b] Dr. R. Rodríguez, Prof. E. Quiñoá, Prof. F. Freire
Centro Singular de Investigación en Química Biolóxica e Materials Moleculares (CIQUS) and Departamento de Química Orgánica
Universidade de Santiago de Compostela
Santiago de Compostela 15782, Spain
E-mail: felix.freire@usc.es
Supporting information for this article is given via a link at the end of the document.

\begin{abstract}
Poly(phenylacetylene)s is a family of helical polymers constituted by conjugated double bonds that are fixed into specific helical structures due to supramolecular and/or steric interactions between pendant groups. Raman spectra of these polymers show a structural fingerprint of the polyene backbone which, in combination with its helical orientation, make them great candidates to study their helical structure by Raman Optical Activity (ROA). Thus, different (i.e., four) well-known poly(phenylacetylene)s adopting different scaffolds and different helical senses (i.e., ten) have been prepared. Raman and ROA spectra were recorded and allow us to stablish a ROA spectrum/helical sense relationship: a right-handed orientation of the polyene backbone $\left(\mathrm{P}_{\text {helix }}\right)$ produces a negative ROA spectrum, whereas a Mhelix produces a positive ROA pattern. In addition, it was found that ROA can be useful for the helical sense assignment of those poly(phenylacetylene)s showing an extra Cotton band in the ECD spectrum. In these cases, a wrong helical sense is assigned based on ECD, while ROA alerts of this helical sense misassignment.
\end{abstract}

\section{Introduction}

The generation of new functional materials based on helical polymers is directly related to the actuation on their helical structure - backbone elongation and helical sense- - . Thus, to study the structure/function relationships of these materials is necessary to have capable tools to elucidate the secondary structure of these complex macromolecules. Nowadays, the structural elucidation of some helical polymers such as poly(phenylacetylene)s (PPAs) $)^{[1-5]}$ this is still a challenge due to the difficulty in obtaining information about the different helical parameters, i.e., helical pitch and sense. ${ }^{[6]}$ Thus, to build up an approximate helical structure of a PPA it is necessary to cross information from different structural and spectroscopic techniques. Many of these techniques are not valid to characterize helical polymers due to the intrinsic properties of the polymers, where the same fragment is repeated along the polymer chain (monomer repeating unit), making powerful structural techniques such as NMR almost useless (Figure 1a). The case is even more challenging in PPAs which are formed by two coaxial helices, an internal helix described by the polyene covalent backbone and an external helix described by the pendants, which can rotate either in the same or opposite senses depending on the dihedral angle between the conjugated double bonds (Figure $1 \mathrm{~b}-\mathrm{c}$ ). ${ }^{[6,7]}$
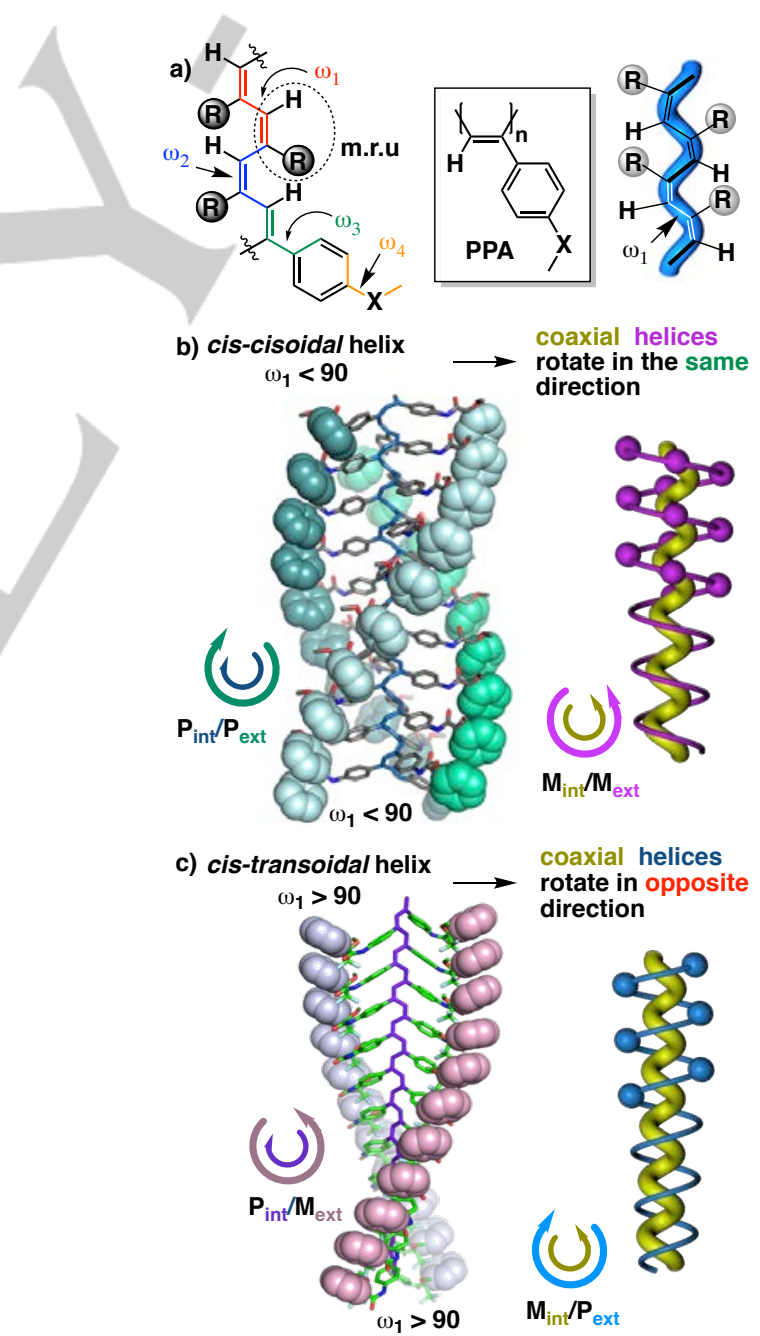

Figure 1. (a) Main dihedral angles of a poly(phenylacetylene) and its folding into a helix. 3D model and schematic representation of PPAs showing two different scaffolds where the coaxial helices rotate in (b) the same -cis-cisoidal- or (c) opposite direction —cis-transoidal-. 
In PPAs, the helical structure is not defined by supramolecular interactions between different residues along the backbone as it happens for instance in peptides. In this case the helix is defined by steric interactions among pendants, which can originate many different possibilities depending on the dihedral angle between conjugated double bonds ( $\omega_{1}$ in Figure $\left.1 a\right)$. Thus, if the dihedral angle between conjugated double bonds is higher than $90^{\circ}$ (i.e., $\omega_{1}>90^{\circ}$ ), the polymer adopts a cis-transoidal polyene configuration -internal and external helices rotate in opposite directions- (Figure 1c), while if $\omega_{1}<90^{\circ}$ the polymer adopts a cis-cisoidal backbone -internal and external helices rotate in the same direction- (Figures 1b).

Solid-state structural techniques such as X-ray diffraction $(\mathrm{XRD}),{ }^{[8-18]}$ or atomic force microscopy (AFM) ${ }^{[19-27]}$ can be used to provide insights of the helical pitch, length and helix width, although are silent about the internal helical sense (Figure 2). Another restriction of AFM is that can provide structural information, such as the helical sense of the external helix (Figure 2 ), only when $2 \mathrm{D}$ crystals are available or self-assembled monolayers due to the need of getting high-resolution images. ${ }^{[19-}$ 27]

Vibrational Circular Dichroism (VCD) has been also used to gain information about the orientation of the external helix in PPAs. ${ }^{[29]}$ In such case, the solvent used to perform the experiments will interact with the pendant groups of the PPA forming another supramolecular helix with the same orientation than that of the external part of the PPA helix. As a result, the solvent becomes VCD active, and its sign reflects the orientation of the external part of the helix (Figure 2).

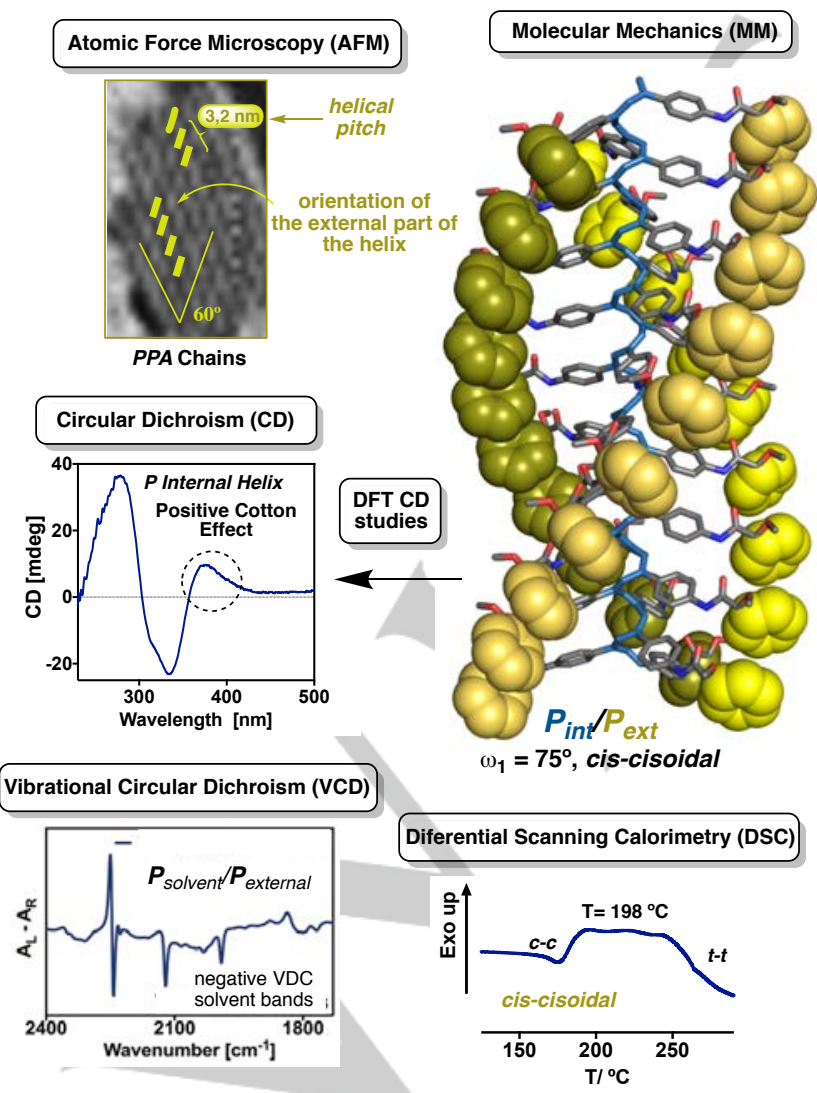

Figure 2. Combination of structural information obtained from a PPA by different structural techniques such as AFM, DSC, MM, DFT, ECD and VCD.
Other techniques such as Differential Scanning Calorimetry (DSC) have also been used in the structure elucidation of poly(phenylacetylene)s. ${ }^{[30-32]}$ DSC provides information about the configuration of the polyene backbone - cis-cisoidal (c-c) and cistransoidal ( $c-t)$ - associated to different and characteristic thermograms ${ }^{[28]}$ (Figure 2). Unfortunately, these studies are frequently limited by the poor definition of the thermograms or by the presence of peaks associated to conformational changes in the pendants, making the assignments unreliable.

Recently, it was also shown that consideration of experimental methods with theoretical calculations can be used to determine the secondary structure of some helical polymers different from PPAs, for instance by combining VCD, ${ }^{[30-32]}$ Electronic Circular Dichroism (ECD) simulations and MMFF94 ${ }^{[33]}$ energy minimization. In this regard, lately, we found that it is possible to determine the $P / M$ internal helical sense of a PPA from its ECD spectra (first Cotton effect). This conclusion is based on the correlations observed between experiments and time-dependent density functional theory (TD-DFT) which provides calculated ECD spectra of a series of PPAs with different and well-known helical scaffolds (Figure 2). ${ }^{[34-35]}$ Thus, a positive Cotton effect at the UV-vis absorption vinylic region corresponds to a $P$ helical (internal) sense, while a negative Cotton effect indicates the presence of a $M$ helix for the polyene skeleton. A detrimental point of this approach is that in some cases, this helical sense assignment is not straightforward. Some PPAs shows an extra Cotton band associated to a $\omega_{3}$ rotation. This Cotton band usually appears at higher wavelengths, overlapping the first Cotton effect in the ECD trace, which could lead to wrong helical sense assignments.

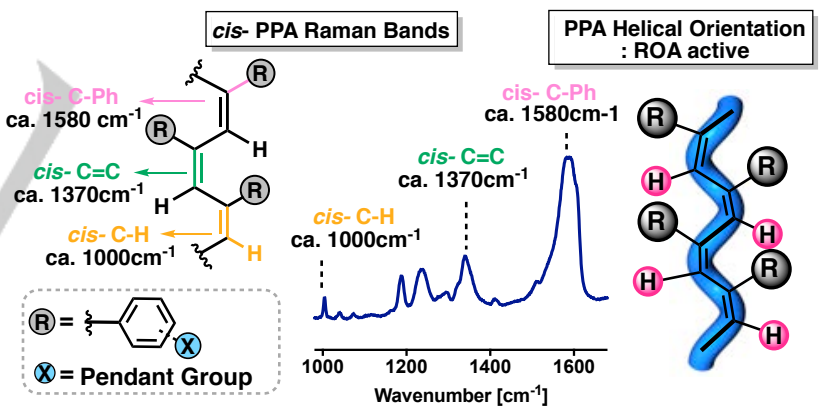

Scheme 1. Schematic representation of a PPA showing its helical rearrangements and the Raman bands associated to the polyphenylacetylene backbone.

Herein, Raman Optical Activity (ROA) ${ }^{[36-42]}$ is introduced as a novel technique to study the helical structure of PPAs, which by itself or by complementing other structural techniques will allow us to undoubtedly assign the internal sense of the helix of PPAs.

\section{Results and Discussion}

Poly(phenylacetylene)s show strong Raman bands associated to the main vibrations of the backbone chain - $\mathrm{CC}$ stretching of the $\mathrm{Ph}$ group of the cis-C-Ph moiety ca. $1580 \mathrm{~cm}^{-1}, \mathrm{CC}$ stretching of cis- $\mathrm{C}=\mathrm{C}$ ca. $1370 \mathrm{~cm}^{-1}, \mathrm{CH}$ deformation mode of the cis-C-H ca. $1000 \mathrm{~cm}^{-1}$, and $\mathrm{CC}$ stretching of the C-C moieties ca. $900 \mathrm{~cm}^{-1}$ - 
Moreover, the tunability of the chiral orientation of this chain into a $P$ or $M$ helical sense as well as the elongation ability (ciscisoidal/compressed, cis-transoidal/stretched) by using external stimuli ${ }^{[43-47]}$, make these polymers great candidates to study their folding by ROA spectroscopy (Scheme 1).

To perform these studies, we chose as a model polymer, a PPA that bears the para-ethynylbenzamides of the $(S)$-Valine methyl ester as pendant group (poly-1, Figure 3a). ${ }^{[48]}$ This is a dynamic polymer whose helical sense can be inverted by the polar character of the solvent (Figure $3 b$ ) used. Thus, in non-polar solvents such as DCM, the ECD spectrum shows a first negative Cotton effect (Figure 3c), the one appearing at higher wavelengths, which corresponds to an $M$ helical structure of the polyene backbone induced by an antiperiplanar orientation of the carbonyl groups at the pendant (Figure 3e). On the other hand, in polar solvents such as a $\mathrm{MeOH} / \mathrm{DCM}$ mixture, a first positive Cotton effect is obtained (Figure 3c), indicating the presence of a $P$ helix induced by the presence of a major synperiplanar conformation of the carbonyl groups at the pendant (Figure 3f).

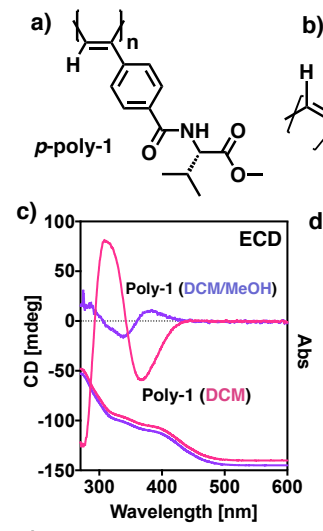

e)
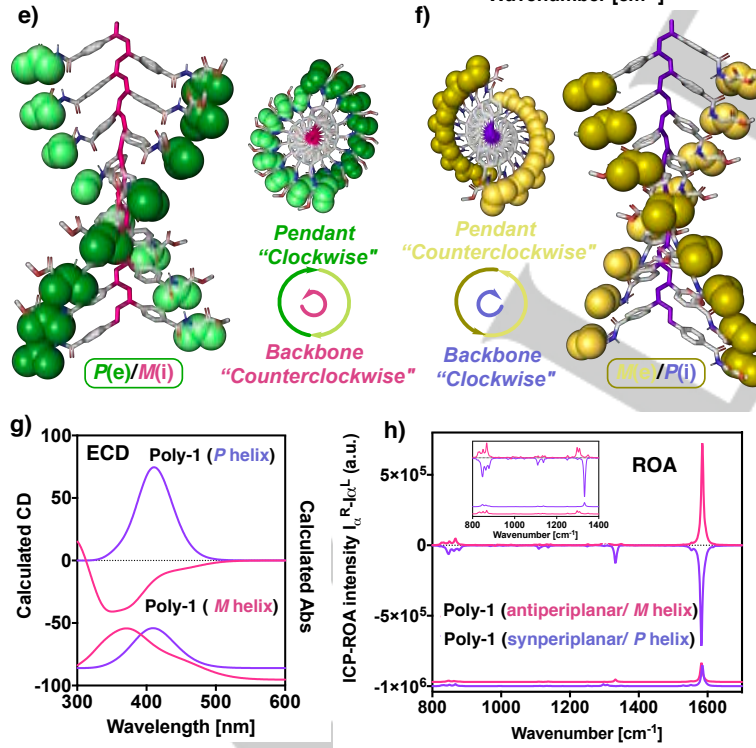

Figure 3. (a) Structure of poly-1. (b) Poly-1 main conformers in low-polar and polar media. (c) ECD/UV and (d) Raman/ROA spectra of poly-1 in low-polar (DCM) and polar solvents (DCM/MeOH). 3D graphical representation of an oligomer $(n=16)$ cis-transoidal structure for poly-1 with a (e) $M$ and (f) $P$ helical sense of the polyene backbone. Calculated (g) ECD/UV and (h) Raman/ROA spectra for the two helical orientations of an oligomeric structure of poly-1.
DSC studies of poly-1 in polar and low-polar solvents show a classical thermogram for a cis-transoidal polyene backbone $\omega_{11}>$ $90^{\circ}$ ), where the helical scaffold is stabilized by $\mathrm{H}$-bonds between amide groups in $i$ and $i+2$ positions along the polymer chain (See ESI). TD-DFT calculations on the $M$ helix of a cis-transoidal oligomer model $(n=10)$ of poly-1 shows a first negative Cotton effect which is coincident with the experimental ECD spectrum obtained in non-polar solvents. On the other hand, identical studies on a $P$ helix of an oligomer model $(n=10)$ of poly- 1 shows a first positive Cotton effect, which is in agreement with the experimental one.

Next, Raman and ROA studies in Figure 3 have been performed for poly-1 in both non-polar and polar solvents -DCM and $\mathrm{DCM} / \mathrm{MeOH}$ - (Figure 3d). The absence of pendant bands in the different Raman and ROA spectra clearly indicates that the PPA backbone is the active chromophore with bands assigned to CC stretching of the Ph group of the cis-C-Ph moiety ca. $1580 \mathrm{~cm}^{-1}$, CC stretching of cis-C=C ca. $1370 \mathrm{~cm}^{-1}$ and $\mathrm{CC}$ stretching of the C-C moieties ca. $900 \mathrm{~cm}^{-1}$. Interestingly, we could observe how the ROA spectra is sensitive to the chiral orientation of the polyene backbone since almost mirror image spectra were obtained for this PPA dissolved in solvents with different polarity which is assigned to the presence of opposite helical senses of the same polyene backbone. Thus, in DCM —non-polar solventa full positive ROA spectrum was obtained which corresponds to negative pattern of the first Cotton polyene band at $380 \mathrm{~nm}$ of the ECD spectrum. Both the positive ROA and the negative ECD consistently reveal $M$ helical orientation of the PPA backbone. The opposite situation was found for poly-1 in a $D C M / M e O H$ mixture - polar solvent-, where a negative ROA spectrum and a positive ECD signals were obtained both indicating a $P$ helix. DFT calculations ${ }^{[49-57]}$ on the $M$ helix of a model oligomer $(n=10)$ of poly-1 shows a full positive ROA spectrum, matching the results obtained experimentally. On the other hand, ROA calculations on the $P$ helix of a model oligomer $(n=10)$ of poly-1 shows a full negative spectrum such in the experimental measure, indicating an opposite orientation of the polyene backbone. Importantly, in this case ECD and ROA predict the same helical sense of the polyene backbone.

Next, we explore the ability of ROA to elucidate the helical structure of a PPA that bears the meta-ethynylbenzamide of the (S)-phenylglycine methyl ester as pendant group ( $m$-poly-2) (Figure 4a). ${ }^{[6]}$ Interestingly, this polymer shows in non-polar solvents (DCM) a combination of two different cis-transoidal helical scaffolds in equilibrium — stretched/compressed - (Figure $4 \mathrm{~b}$ ), oriented into the same $M$ helical sense (two negative Cotton effects at the polyene region at ca. 365 and $442 \mathrm{~nm}$ ), while in polar solvents (DMSO) a single compressed cis-transoidal $M$ helix is obtained (negative Cotton effect at $380 \mathrm{~nm}$, Figure 4c).

Raman and ROA experiments show again that only the poly(phenylacetylene) backbone is active - $\mathrm{CC}$ stretching of the $\mathrm{Ph}$ group of the cis-C-Ph moiety ca. $1580 \mathrm{~cm}^{-1}$, CC stretching of cis- $\mathrm{C}=\mathrm{C}$ ca. $1370 \mathrm{~cm}^{-1}, \mathrm{CH}$ deformation mode of the cis-C-H ca. $1000 \mathrm{~cm}^{-1}$, and CC stretching of the C-C moieties ca. $900 \mathrm{~cm}^{-1}-$. In this case, ROA spectra obtained for poly-2 in polar and nonpolar solvents are almost identical, showing a positive sign in the full spectra, opposite to the negative sign of the Cotton effect corresponding to the polyene bands in the ECD spectra of $m$-poly2. Therefore, these results indicate that an $M$ orientation for the polyene backbone produces a negative Cotton effect for the polyene backbone in the ECD spectrum, while ROA shows a full 
positive spectrum. TD-DFT and ROA calculations on the $M$ helix of a model oligomer $(n=10)$ of $m$-poly-2 fulfill the results obtained experimentally, a negative Cotton effect in the ECD spectrum for the polyene band and a full positive ROA spectrum. Again, such as in poly-1 ECD and ROA, conclusions are fully coincident revealing the presence of a $\mathrm{M}$ helix in both cases.
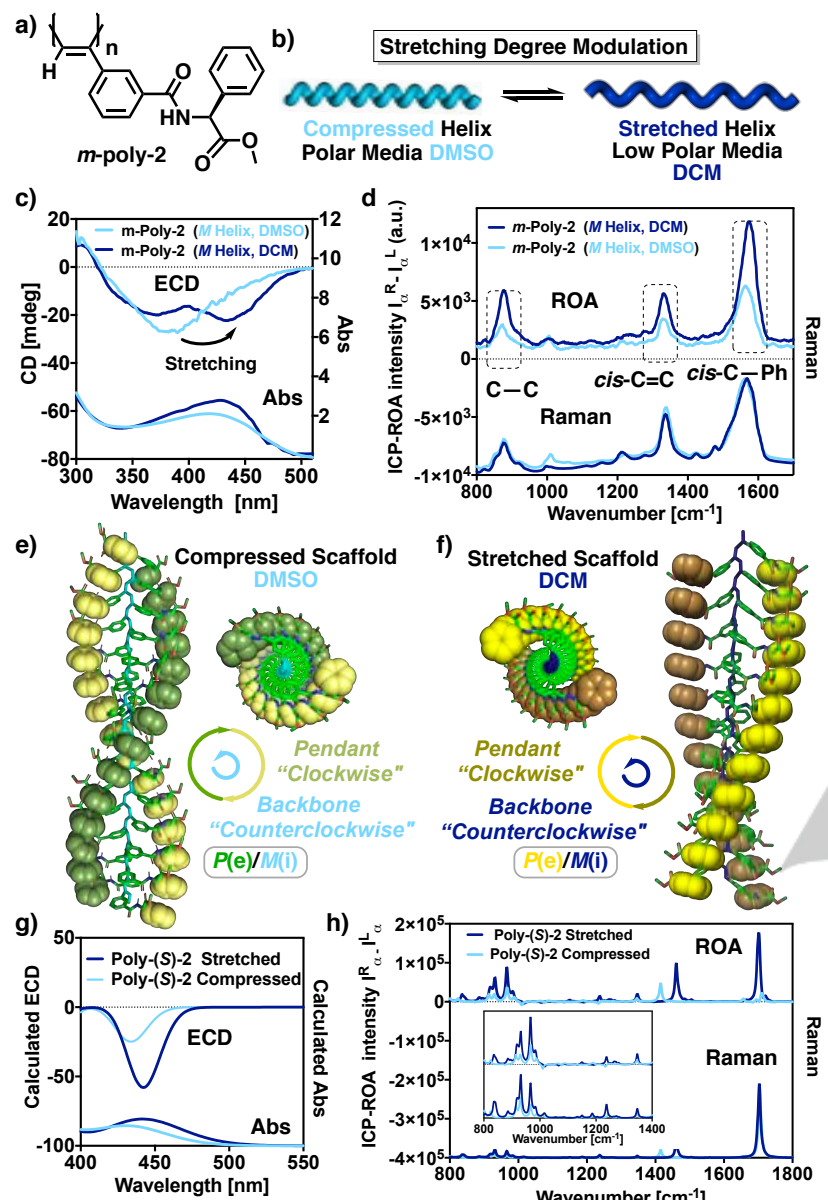

$$
\text { (1) }
$$$$
\text { . }
$$
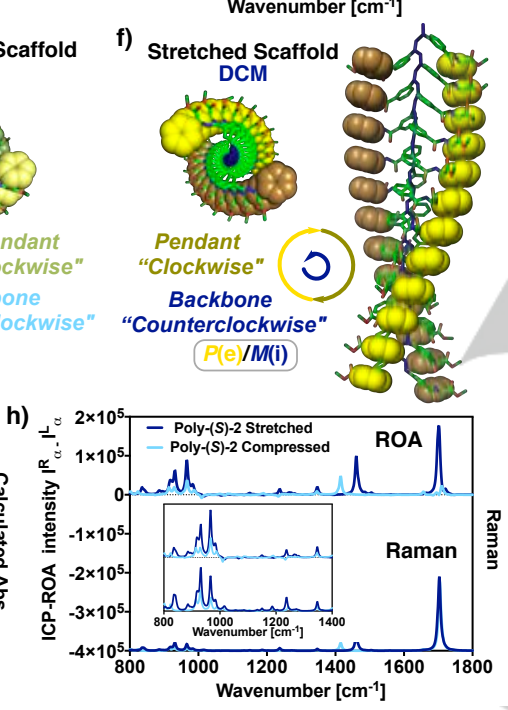

Figure 4. (a) Structure of $m$-poly-2. (b) Schematic representation of the compressed and stretched $M$ helical scaffolds obtained for $m$-poly-2. (c) ECD/UV and (d) Raman/ROA spectra of $m$-poly-2 in low-polar (DCM) and polar solvents (DMSO). 3D graphical representation of an oligomer $(n=24)$ cistransoidal structure for $m$-poly-2 with different cis-transoidal polyene backbones. Calculated (g) ECD/UV and $(\mathrm{h})$ Raman/ROA spectra for the two helical orientations of an oligomeric structure of $m$-poly-2.

Let's go now with helical poly(phenylacetylene)s that show a more complicated ECD spectrum. In particular those PPAs that adopt a kind of helical structures that generate ECD traces with three alternating Cotton effects. In such case, the first Cotton band is assigned to the polyene backbone and therefore it is a marker of the helical sense of the polymer. Occasionally, a new band is generated (Figure 5a) giving rise to an ECD trace with four alternating Cotton effects. ${ }^{[35]}$ This new feature appears at higher wavelengths and is assigned as the results of a $\omega_{3}$ rotation. In these cases, the first Cotton effect is not associated to the polyene backbone and can lead to helical misassignment. Therefore, to elucidate the right helical sense of the polyene backbone it is necessary first to determine which Cotton band corresponds to the main chain.
We decided to test the reliability of ROA in a polymer that show this feature. We chose, as an example, the para-substituted isomer of poly-2 ( $p$-poly-2). ${ }^{[58]}$ This polymer behaves in a similar manner than poly-1 where the two helical senses can be induced in the polymer by acting on the conformational composition of the pendant group through changes on the solvent polarity. Thus, in non-polar solvents (DCM), a $M$ cis-transoidal helical structure of the polyene backbone is induced due to the presence of an antiperiplanar orientation of the carbonyl groups at the pendant, while in polar solvents (DMSO) an $P$ cis-transoidal helix is generated (Figure $5 \mathrm{~b}-\mathrm{c}$ ) due to a synperiplanar orientation of the carbonyl groups.
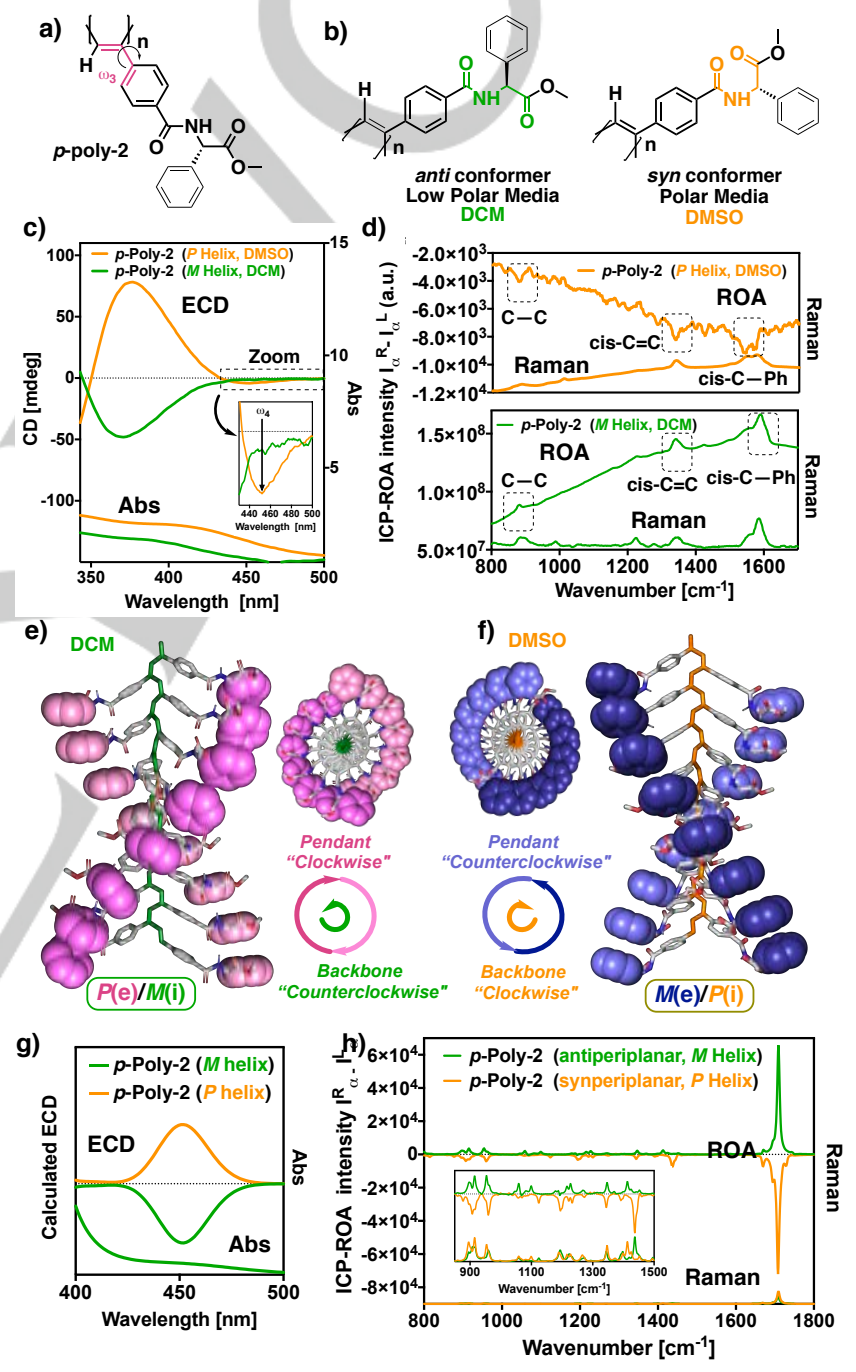

Figure 5. (a) Structure of $p$-poly-2. (b) p-poly-2 main conformers in low-polar and polar media. (c) ECD/UV and (d) Raman/ROA spectra of $p$-poly-2 in lowpolar (DCM) and polar solvents (DMSO). 3D graphical representation of an oligomer $(n=24)$ cis-transoidal structure for $p$-poly-2 with different cis-transoidal polyene backbones. Calculated (g) ECD/UV and (h) Raman/ROA spectra for the two helical orientations of an oligomeric structure of $p$-poly-2.

Looking at the ECD spectrum of p-poly-2 in DMSO we can observe the presence of an extra band at ca. $460 \mathrm{~nm}$, which is assigned to a rotation around the $\omega_{3}$ bond, as aforementioned, and not intrinsically to the polyene backbone. In this particular situation, the helical sense of the PPA is extracted from the 
second Cotton effect $(390 \mathrm{~nm})$, which has an opposite sign relative to the first one: this scenario can lead to helical sense misassignments if the first one is chosen to assign the helical sense of the PPA.

Raman and ROA experiments evidence again for $p$-poly-2 that only the poly(phenylacetylene) backbone is active, showing opposite orientations of the polyene backbone due to the mirror image relationship - ROA (+) in non-polar solvents and ROA (-) in polar solvents-. Interestingly, in polar solvents (DMSO), the sign of the ROA spectrum is as expected from previous studies (see above), opposite to the second Cotton effect assigned to the polyene backbone, and not to the first one assigned to a $\omega_{3}$ rotation. Moreover, the intensity of the ROA spectrum in DMSO is very weak in comparison with the one obtained in DCM, indicating that the magnitude of the spectra is affected by the rotation of $\omega_{3}$, and therefore by the presence of an extra band in the ECD spectra. However, conversely to ECD, ROA is straightforward and is exclusively sensitive to the right sense of the polyacetylene helix.

Finally, to further test the reliability of ROA in the structural elucidation of PPAs, we choose one obtained from the polymerization of the para-ethynylanilide of the $(R)$ - $\alpha$-methoxy- $\alpha$ trifluoromethylphenylacetic acid as pendant group (poly-3, Figure 6). ${ }^{[7]}$ This polymer can adopt four different helical structures attending to the donor and polar character of the solvent. Thus, in the case of non-donor solvents a compressed helical structure is generated due to the presence of a major anti conformation for the amide bond of the anilide group. In these non-donor solvents, the helical sense of the polymer can be tuned by changing the polar character of the solvent. Thus, in non-polar/non-donor solvents, the $\mathrm{O}=\mathrm{C}-\mathrm{C}-\mathrm{O}$ bond adopts a major antiperiplanar (ap) conformation between the carbonyl and the methoxy group, while in polar/non-donor solvents this bond adopts a preferred synperiplanar conformation (ap) (Figure 6b).

To carry out our structural studies on poly-3, we dissolved the polymer in chloroform -non donor/non-polar- and in a $\mathrm{CHCl}_{3} / \mathrm{DMSO}$ mixture (4/1) -non donor/polar-. In these solvents, ECD studies showed the induction of opposite helical senses. Thus, while $\mathrm{CHCl}_{3}$ induces a negative Cotton effect in the vinylic region and therefore an $M$ helical sense of the polyene backbone, a positive Cotton effect is induced in DMSO which corresponds to a $P$ right-handed helix (Figure 6c).

ROA experiments show also spectra with opposite sign in these two media, indicating the presence of backbones with opposite helical senses (Figure 6d). As expected, the ROA spectra are opposite to the first Cotton effect observed in ECD, which corresponds to the polyene backbone $[P$ helix: ECD (+)/ROA (-); $M$ helix: ECD (+)/ROA (-)] (Figure $6 \mathrm{c}-\mathrm{f})$. In donor solvents poly-3 adopts a stretched helix due to the presence of a major cis conformation for the amide bond of the anilide group (Figure 6a). Moreover, the helical sense of the polymer can be tuned in donor solvents by changing the polar character of the solvent. Similar to non-donor media, in low-polar/donor solvents the $\mathrm{O}=\mathrm{C}-\mathrm{C}-\mathrm{O}$ bond, adopts a major antiperiplanar (ap) conformation between the carbonyl and the methoxy group, while in polar/donor solvents this bond adopts a preferred synperiplanar conformation (ap) (Figure 6b).
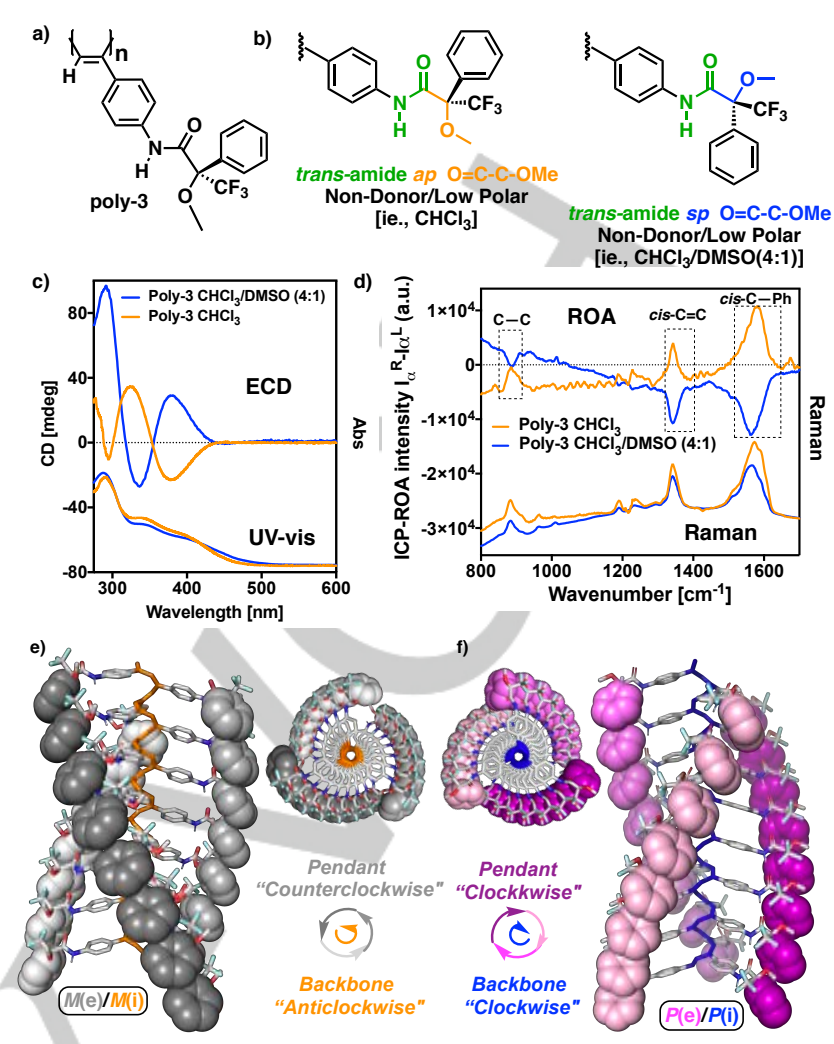

Figure 6. a) Structure of poly-3. b) poly-3 main conformers in non-donor solvents with low-polar and polar behavior. c) ECD/UV and (d) Raman/ROA spectra of poly-3 in low-polar $\left(\mathrm{CHCl}_{3}\right)$ and polar solvents $\left(\mathrm{CHCl}_{3} / \mathrm{DMSO} 4 / 1 \mathrm{v} / \mathrm{v}\right)$. 3D cis-cisoidal structures $(\mathrm{n}=24)$ of poly-3 with different (e) $M$ and (f) $P$ helical senses $\left[\mathrm{CHCl}_{3}\right.$ and $\mathrm{CHCl}_{3} / \mathrm{DMSO}(4: 1)$ respectively].

Thus, UV, ECD, Raman and ROA studies were performed for poly-3 in donor solvents such as THF (donor/low-polar) and a 1:1 $\mathrm{CHCl}_{3}$-DMSO mixture (donor/ polar). As expected, ECD spectra show mirror traces indicating the presence of helices with opposite helical senses (Figure 7a-b). Interestingly, in these ECD spectra it is possible to observe the presence of an extra feature around $450 \mathrm{~nm}$ which is more intense than the one observed previously in $m$-poly-2 (Figure 4c).

ROA studies of poly-3 in donor solvents show a strong dependence with $\omega_{3}$. Thus, the ROA spectra show opposite sign to the first Cotton effect band which corresponds to a $\omega_{3}$ rotation, and not to the polyene backbone ( $2^{\text {nd }}$ Cotton effect at c.a. $\left.380 \mathrm{~nm}\right)$. Intriguingly, the ROA spectra does not show the same pattern than the ones observed previously. In this particular case, ROA spectra do not show the C-C band at ca. $900 \mathrm{~cm}^{-1}$, being absent in both cases, THF and a 1:1 $\mathrm{CHCl}_{3}$-DMSO mixture (Figure $7 \mathrm{~b}-\mathrm{C}$ ). In order to remove the $\omega_{3}$ effect in the ECD spectra, we played with different donor/non-polar mixtures. It was found that when poly-3 is dissolved in a $1: 1 \mathrm{CHCl}_{3} /$ Dioxane mixture (donor/nonpolar), the ECD spectra resemble the one obtained in THF (donor/non-polar) with the absence of the Cotton effect associated to $\omega_{3}$ (Figure 8). 


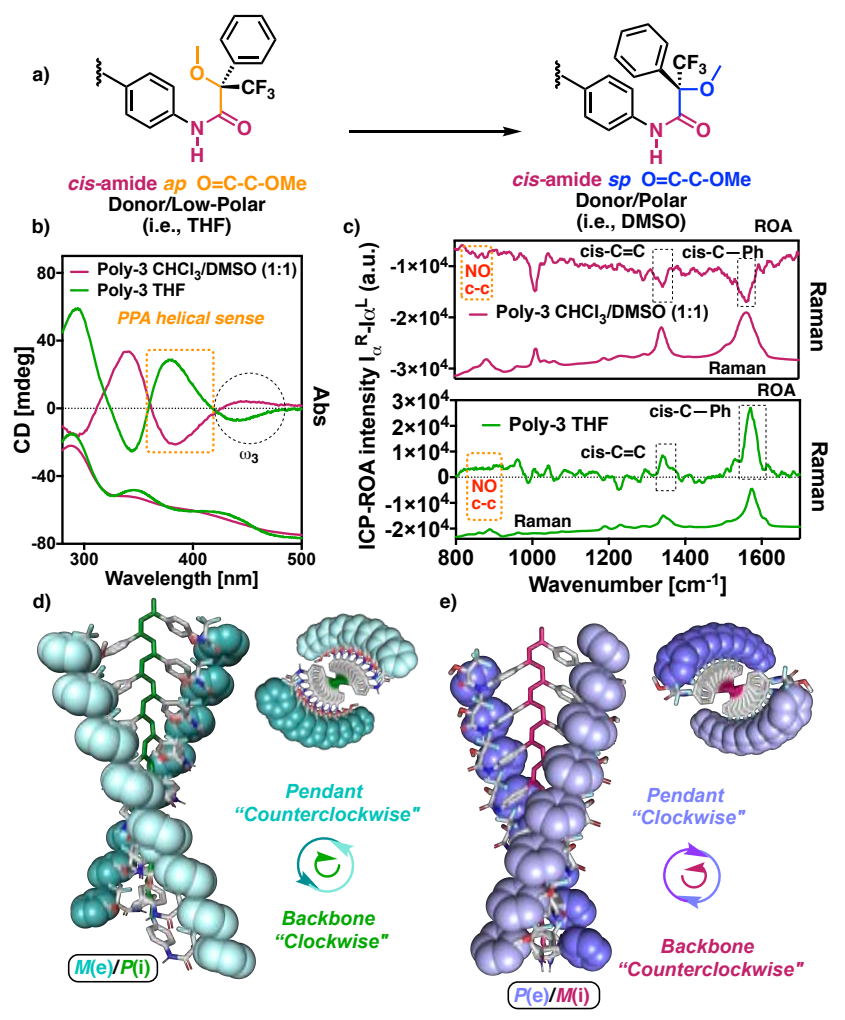

Figure 7. (a) Poly-3 main conformers in non-donor solvents with low-polar and polar parameters. (b) ECD/UV and (c) Raman/ROA spectra of poly-3 in donorpolar $\left(\mathrm{CHCl}_{3} / \mathrm{DMSO}\right)$ and donor-low polar solvents (THF) (top and bottom spectra respectively). 3D cis-transoidal structures $(n=16)$ of poly-3 in (d) THF and (e) $\mathrm{CHCl} 3 / \mathrm{DMSO}(1: 1)$

ROA studies of poly-3 in this solvent mixture show a ROA trace with the three characteristic peaks of the main chain - cis- $\mathrm{C}-\mathrm{Ph}$, cis- $\mathrm{C}=\mathrm{C}$ and the $\mathrm{C}-\mathrm{C}-$ and opposite sign to the $\mathrm{ECD}$ band of the polyene backbone - ECD (+) at $380 \mathrm{~nm} / \mathrm{ROA}$ trace (-)which corresponds to an $P$ helix (Figure 8).

This fact clearly indicates that rotation on $\omega_{3}$ has a strong effect on the ECD and ROA spectra. In ECD a new Cotton effect band is generated at higher wavelengths which makes difficult to assign the helical sense of the PPA. On the other hand, ROA shows a trace with the absence of the $\mathrm{C}-\mathrm{C}$ band, indicating that the associated Cotton effect is not related to the helical sense of the main chain.
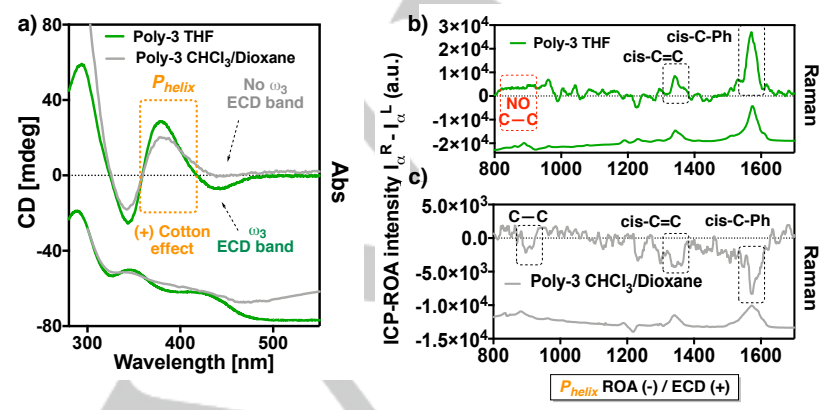

Figure 8. a) ECD spectra of poly-3 in donor/non-polar solvents showing either four (THF) or three $\left(\mathrm{CHCl}_{3}\right.$ /Dioxane) alternating Cotton effects. ROA spectrum of poly-3 in (b) THF and (c) a $\mathrm{CHCl}_{3} /$ Dioxane mixture.
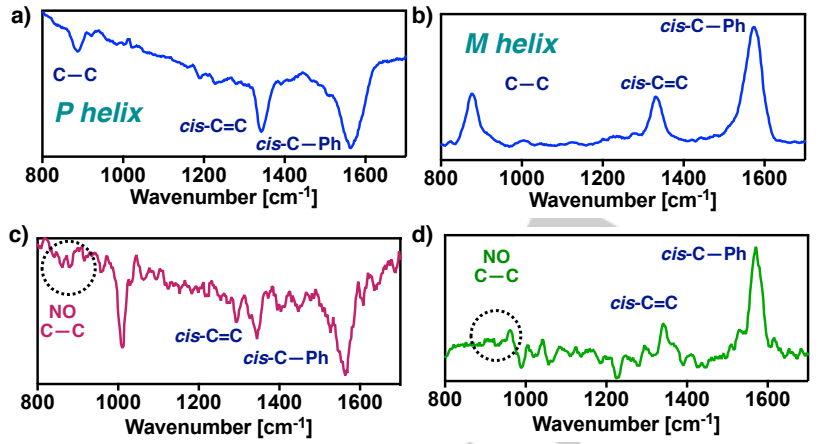

Figure 9. ROA spectrum of a PPA with a (a) $P$ helix, (b) $M$ helix and a (c-d) $\omega_{3}$ interference.

\section{Conclusion}

In conclusion, it was demonstrated through a good number of examples -4 polymers, 10 helical structures - that ROA is a powerful structural technique, which can be used in the helical sense assignment of PPAs. During these studies it was found that a ROA spectrum showing the three characteristic vibrational bands of the polyene backbone associated stretching modes of the cis- $\mathrm{C}-\mathrm{Ph}$, cis- $\mathrm{C}=\mathrm{C}$ and $\mathrm{C}-\mathrm{C}$ moieties can be correlated with the helical sense of the main chain attending to sign of the ROA spectrum — positive ROA/M helix; negative ROA $/ P_{\text {helix }}$ (Figure 9ab). Moreover, it was also found that some PPAs produce in certain solvent conditions a ROA spectrum that lack the $\mathrm{C}-\mathrm{C}$ band. This ROA spectrum is related to a rotation around the $\omega_{3}$ and not to the polyene backbone which produces also an extra Cotton band in the ECD spectrum. In this case, the lack of the $\mathrm{C}-\mathrm{C}$ band in the ROA spectrum is an alert sign which indicates that neither the ROA nor ECD - first Cotton band- are indicating the correct helical sense of the polymer (Figure 9c-d). To do a correct helical sense assignment in these cases it is necessary to look for a solvent where the three characteristic peaks of the polyene backbone appear in the ROA spectra.

Thus, the robustness of ROA in the helical sense elucidation of PPAs and its potential application in other families of helical polymers -with or without chromophores-has been clearly demonstrated along these studies.

\section{Acknowledgements}

Financial support from MINECO (PGC2018-098533-B-I00, CTQ2015-70519-P and the Junta de Andalucía project reference (UMA18-FEDERJA-057) are acknowledged. Xunta de Galicia (ED431C 2018/30, Centro singular de investigación de Galicia accreditation 2016-2019, ED431G/09 and postdoctoral fellowship for R. R.) and the European Regional Development Fund (ERDF) are also gratefully acknowledged,

Keywords: Raman Optical Activity • Helical Polymers • Helical Sense $\bullet$ Poly(phenylacetylene)s $\bullet$ Circular Dichroism

[1] F. Freire, E. Quiñoá, R. Riguera, Chem. Commun., 2017, 53, 481-492.

[2] F. Freire, E. Quiñoá, R. Riguera, Chem. Rev., 2016, 116, 1242-1271.

[3] E. Yashima, N. Ousaka, D. Taura, K. Shimomura, T. Ikai, K. Maeda, Chem. Rev., 2016, 116, 13752- 13990. 
[4] E. Yashima, K. Maeda, H. Lida, Y. Furusho, K. Nagai, Chem. Rev. 2009, 109, 6102-6211.

[5] J. Liu, J. W. Y. Lam, B. Z. Tang, B. Z. Chem. Rev. 2009, 109, 5799-5867.

[6] R. Rodrígez, E. Quiñoá, R. Riguera, F. Freire, J. Am. Chem. Soc., 2016, 138, 9620-9628.

[7] S. Leiras, F. Freire, J. M. Seco, E. Quiñoá, R. Riguera, Chem. Sci. 2013 4, 2735-2743.

[8] K. Nagai, K. Sakajiri, K. Maeda, K. Okoshi, T. Sato, E. Yashima, Macromolecules 2006, 39, 5371-5380.

[9] M. Morimoto, K. Tamura, K. Nagai, E. Yashima, J. Polym. Sci., Part A: Polym. Chem. 2010, 48, 1383-1390.

[10] T. Fukushima, H. Kimura, K. Tsuchihara, Macromolecules 2009, 42 8619-8626.

[11] K. Okoshi, T. Kajitani, K. Nagai, E. Yashima, Macromolecules 2008, 41, 258-261

[12] Y. Mawatari, M. Tabata, T. Sone, K. Ito, Y. Sadahiro, Macromolecules 2001, 34, 3776-3782.

[13] A. Motoshige, Y. Mawatari, R. Motoshige, Y. Yoshida, M. Tabata, J. Polym. Sci., Part A: Polym. Chem. 2013, 51, 5177-5183.

[14] R. Motoshige, Y. Mawatari, A. Motoshige, Y. Yoshida, T. Sasaki, H. Yoshimizu, T. Suzuki, Y. Tsujita, M. Tabata, J. Polym. Sci., Part A: Polym. Chem. 2014, 52, 752-759.

[15] V. Percec, J. G. Rudick, M. Peterca, M. Wagner, M. Obata, C. M. Mitchell, W-D. Cho, J. Am. Chem. Soc. 2005, 127, 15257-15264.

[16] V. Percec, M. Peterca, J. G. Rudick, E. Aqad, M. R. Imam, P. A. Heiney, Chem. Eur. J. 2007, 13, 9572-9581.

[17] V. Percec, E. Aqad, M. Peterca, J. G. Rudick, L. Lemon, J. C. Ronda, B. B. De, P. A. Heiney, E. W. Meijer, J. Am. Chem. Soc. 2006, 128, 16365 16372.

[18] V. Percec, J. G. Rudick, M. Peterca, E. Aqad, M. R. Imam, P. A. Heiney, J. Polym. Sci., Part A: Polym. Chem. 2007, 45, 4974-4987.

[19] S. Sakurai, K. Okoshi, J. Kumaki, E. Yashima, E. J. Am. Chem. Soc. 2006, 128, 5650-5651.

[20] S. Sakurai, K. Okoshi, J. Kumaki, E. Yashima, Angew. Chem. Int. Ed. 2006, 45, 1245-1248.

[21] T. Nishimura, K. Takatani, S. Sakurai, K. Maeda, E. Yashima, Angew. Chem. Int. Ed. 2002, 41, 3602-3604.

[22] S. Sakurai, A. Ohira, Y. Suzuki, R. Fujito, T. Nishimura, M. Kunitake, E. Yashima, J. Polym. Sci. Part A: Polym. Chem. 2009, 47, 4621-4640.

[23] K. Okoshi, S. Sakurai, S. Ohsawa, J. Kumaki, E. Yashima, Angew. Chem. Int. Ed. 2006, 45, 8173-8176.

[24] S. Sakurai, S. Ohsawa, N. Kanji, K. Okoshi, J. Kumaki, E. Yashima, Angew. Chem. Int. Ed. 2007, 46, 7605-7608.

[25] S. Ohsawa, S. Sakurai, K. Nagai, M. Banno, K. Maeda, J. Kumaki, E. Yashima, J. Am. Chem. Soc. 2011, 133, 108-114.

[26] S. Ohsawa, S. Sakurai, K. Nagai, K. Maeda, J. Kumaki, E. Yashima, Polym. J. 2012, 44, 42-50.

[27] R. Rodríguez, S. Arias, E. Quiñoá, R. Riguera, F. Freire, Nanoscale, 2017, 9, 17752-17757

[28] L. Liu, T. Namikoshi, Y. Zang, T. Aoki, Sh. Hadano, Y. Abe, I. Wasuzu, T. Tsutsuba, M. Teraguchi, T. Kaneko, J. Am. Chem. Soc., 2013, 135, 602-605.

[29] B. Nieto-Ortega, R. Rodríguez, S. Medina, E. Quiñoá, R. Riguera, J. Casado, F. Freire, J. Ramírez, J. Phys. Chem. Lett. 2018, 9, 2266-2270.

[30] Y. Hase, K. Nagai, H. lida, K. Maeda, N. Ochi, K. Sawabe, K. Sakajiri, K. Okoshi, E. Yashima, J. Am. Chem. Soc. 2009, 131, 10719-10732.

[31] T. Kawauchi, J. Kumaki, A. Kitaura, K. Okoshi, H. Kusanagi, K. Kobayashi, T. Sugai, H. Shinohara, E. Yashima. Angew. Chem. Int. Ed. 2008, 47, 515-519.

[32] H. Z. Tang, B. M. Novak, J. Polavarapu, P. L. He, Angew. Chem. Int. Ed. 2005, 44, 7298-7301

[33] Y. Suzuki, J. Tabei, M. Shiotsuki, Y. Inai, F. Sanda, T. Masuda, Macromolecules 2008, 41, 1086-1093.

[34] B. Fernández, R. Rodríguez, A. Rizzo, E. Quiñoá, R. Riguera, F. Freire, Angew. Chem., Int. Ed. 2018, 57, 3666.

[35] B. Fernández, R. Rodríguez, E. Quiñoá, R. Riguera, F. Freire, ACS Omega, 2019, 4, 5233-5240.

[36] P. W. Atkins, L. D. Barron, Mol. Phys., 1969, 16, 453-466.

[37] L. D. Barron, A. D. Buckingham, Mol. Phys., 1971, 20, 1111-1119.
[38] L. A. Nafie, in Vibrational Optical Activity, Principles and Applications, John Wiley and Sons, Chichester, UK, 2011, pp. 133-137.

[39] L. A. Nafie, Chem. Phys. 1996, 205, 309-322.

[40] L. A. Nafie, Theor. Chem. Acc. 2008, 119, 39-55.

[41] G. Li, J. Kessler, J. Cheramy, T. Wu, M. R. Poopari, P. Bouř, Y. Xu, Angew. Chem. Int. Ed. 2019, 58, 16495-16498.

[42] M. G. Lizio, V. Andrushchenko, S. J. Pike, A. D. Peters, G. F. S. Whitehead, I. J. Vitórica-Yrezábal, S. T. Mutter, J. Clayden, P. Bouř, E. W. Blanch, S. J. Webb, Chem. Eur. J. 2018, 24, 9399-9408.

[43] C. Mensch, C. Johannessen, ChemPhysChem, 2018, 19, 3134-3143.

[44] M. Alzubi, S. Arias, R. Rodríguez, E. Quiñoá, R. Riguera, F. Freire, Angew. Chem. Int. Ed. 2019, 58, 13365-13369.

[45] K. Cobos, E. Quiñoa, R. Riguera, F. Freire, J. Am. Chem. Soc. 2018, 140 12239-12246.

[46] S. Arias, F. Freire, M. Calderón, J. Bergueiro, Angew. Chem. Int. Ed., 2017, 56, 11420-11425.

[47] R. Rodríguez, E. Quiñoá, R. Riguera, F. Freire, Small, 2019, 15, 1970070.

[48] S. Arias, M. Núñez-Martínez, E. Quiñoá, R. Riguera, F. Freire, Polym Chem., 2017, 8, 3740-3745.

[49] M. J. Frisch, et al. Gaussian 09, Revision C.01, Gausian, INc. Wallingford CT, 2010.

[50] A. D. Becke, J. Chem. Phys., 1993, 98, 5648-5652.

[51] C. Lee, W. Yang, R. G. Parr, Phys. Rev. B, 1988, 37, 785-789.

[52] Y. Tawada, T. Tsuneda, S. Yanagisawa, T. Yanai, K. Hirao, J. Chem. Phys, 2004, 120, 8425-8433.

[53] P. C. Hariharan, J. A. Pople, Theor. Chim. Acta, 1973, 28, 213-222.

[54] A. P. Scott, L. Radom, J. Phys. Chem. 1996, 100, 16502-16513.

[55] E. Runge, E. K. U. Gross, Phys. Rev. Lett. 1984, 52, 997-1000.

[56] E. K. U. Gross, W. Kohn, Adv. Quant. Chem. 1990, 21, 255-294.

[57] E. J. Heller, Y. Yang, L. Kocia, ACS Cent. Sci. 2015, 1, 40-49.

[58] M. Alzubi, S. Arias, E. Quiñoá, R. Riguera, F. Freire, Chem. Commun., 2017, 53, 8573-8576 


\section{Entry for the Table of Contents}
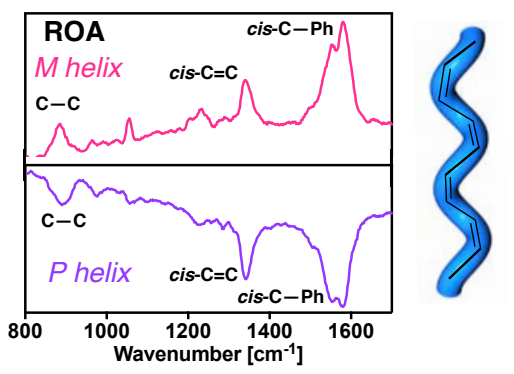

Institute and/or researcher Twitter usernames: @felixfreirelab; @ciqususc 